This document is the accepted manuscript version of the following article: Donatas Gesevičius, Antonia Neels, Sergii Yakunin, Erwin Hack, Maksym V. Kovalenko, Frank Nüesch, and Jakob Heier*, Superweak Coordinating Anion as Superstrong Enhancer of Cyanine Organic Semiconductor Properties, ChemPhysChem 2018, 19, 33563363, DOI: 10.1002/cphc.201800863.

DOI: 10.1002/ ((please add manuscript number))

Article type: Full Paper

\title{
Superweak Coordinating Anion as Superstrong Enhancer of Cyanine Organic
}

\section{Semiconductor Properties}

Dr. Donatas Gesevičius, ${ }^{a, f}$ Prof. Antonia Neels ${ }^{b}$, Dr. Sergii Yakunin, ${ }^{c, d}$ Dr. Erwin Hack, ${ }^{e}$ Prof. Maksym V. Kovalenko, ${ }^{c, d}$ Prof. Frank Nüesch ${ }^{a, g}$ and Dr. Jakob Heier ${ }^{*}, a$

a. Laboratory for Functional Polymers, Swiss Federal Laboratories for Materials Science and Technology, Empa, Überlandstrasse 129, Dübendorf, Switzerland.

b. Center for X-ray Analytics, Swiss Federal Laboratories for Materials Science and Technology, Empa, Überlandstrasse 129, Dübendorf, Switzerland.

c. Laboratory for thin films and photovoltaics, Swiss Federal Laboratories for Materials Science and Technology, Empa, Überlandstrasse 129, Dübendorf, CH-8600, Switzerland.

d. Department of Chemistry and Applied Biosciences, Swiss Federal Institute of Technology Zurich, Vladimir Prelog Weg 1, Zurich,CH-8093, Switzerland.

e. Laboratory for Transport at Nanoscale Interfaces, Swiss Federal Laboratories for Materials Science and Technology, Empa, Überlandstrasse 129, CH-8600 Dübendorf, Switzerland.

f. Institute of Chemical Sciences and Engineering, ISIC, Ecole Polytechnique Fédérale de Lausanne, EPFL, Station 6, CH-1015 Lausanne, Switzerland.

g. Institut des Matériaux, Ecole Polytechnique Fédérale de Lausanne, EPFL, Station 6, CH-1015 Lausanne, Switzerland.

E-mail: jakob.heier@empa.ch

Keywords: superweak coordinating anions, cyanine dyes, fluorescence, lattice energy, organic photovoltaics

The tetrakis(nonafluoro-tert-butoxy)aluminate superweak coordinating anion was employed to introduce pseudo gas-phase conditions to the 2-[5-(1,3-dihydro-1,3,3-trimethyl-2H-indol-2ylidene)-1,3-pentadien-1-yl]-1,3,3-trimethyl-3H-indolium chromophore. The resulting formation of a photoactive organic-inorganic hybrid salt has led to a highly stabilized excited 
state of the organic chromophore mainly due to the minimized lattice energy and Coulomb interactions. These highly beneficial features caused by the well dispersed negative charge of the anion have led to an enhanced neat spin-casted film fluorescence intensity, prolonged fluorescence lifetime, smooth thin film surfaces and a record power photovoltaic efficiency of 3.8\% when compared to organic salts of this particular chromophore containing anions with localised negative charge. Clear evidence is given that a superweak coordinating anion is an emerging key parameter in cyanine dye photochemistry. This approach can be seen as a general guideline to prepare highly efficient ionic dyes for organic semiconductor applications.

\section{Introduction}

The concept of weakly coordinating anions (WCA's) was introduced in the seventies. ${ }^{[1]}$ It was shown that in condensed matter the cation-anion interactions can never reach a non-coordinative state but rather can be minimized, which is commonly called "pseudo gas-phase condition". ${ }^{[2,3]}$ To achieve this state, weakly coordinating anions underwent decades of development. The challenge is rooted into the creation of an anion with a low overall negative charge and its simultaneous delocalisation over the whole molecule. The central core of such anions contains usually strong Lewis acids (B, Al, Ga, Sb, As) which are shielded with large non-polarizable moieties to prevent degradation and eliminate possible basicity and nucleophilic sites. ${ }^{[4]}$ Most commonly, bulky perfluorinated moieties are used with the ability to form additional stabilising fluorine contacts to the Lewis acidic centre. ${ }^{[5]}$ The most common classes of WCA's are the perfluorinated metalates, perfluorinated tetraarylborates, carboranes, alkoxy/aryloxy metalates and teflates..$^{[3,4,6-11]}$ Concerning practical applications of such anions in organic semiconductor research, stability against moisture, oxygen and redox reactions as well as high temperatures is crucial. Due to the large size of up to several 
nanometres, weakly coordinating anions tend to degrade into smaller coordinating species. ${ }^{[12-15]}$ Perfluoroborates exhibit often a high redox tendency which has to be avoided in organic photovoltaic (OPV) applications. ${ }^{[16,17]}$ A more prominent example is the $\mathrm{C}_{60}{ }^{-}$anion whose application in OPV research is ruled out because of its reduction potential below $0 \mathrm{~V}$ vs NHE. ${ }^{[18-20]}$ Considering all mentioned factors, only the perfluorinated alkoxy aluminates, tetrakis(nonafluoro-tert-butoxy)aluminate in particular, unifies the desired properties, making it the least coordinating anion that can be used for OPV applications. ${ }^{[21]}$

Organic semiconductors as such were discovered over 60 years ago and underwent decades of intense research. ${ }^{[22,23]}$ To date, organic salts, especially cyanine dyes represent only a small group among all small molecule organic semiconductors. ${ }^{[24]}$ Comparing anionic and cationic chromophores to neutral chromophores, cyanine dyes exhibit optical properties that outperform their neutral counterparts in many aspects. This is mainly caused by the chromophore geometry, in which an odd numbered polymethine chain is connecting an auxochrome group as well as an antiauxochrome moiety on the other end. ${ }^{[25,26]}$ Considering the structural properties of cyanine dyes it becomes clear why the counterion has such a tremendous influence on the chromophore's electronic, conformational and optical properties; especially in neat spin-casted films and organic electronic devices. ${ }^{[24,27-33]}$ The single positive charge of the chromophore in its ground state electron configuration is compensated by the anion. On the contrary, exciting a cyanine and transferring an electron to an acceptor in an OPV device creates formally a doubly positively charged molecule for a short period, a highly unfavourable state for the cyanine chromophore when considering the standard ionisation potential approach for molecules. ${ }^{[34,35]}$ Additionally, typical exciton radii in organic materials are smaller than the unit cell volume. ${ }^{[36]}$ Therefore in conventional organic semiconductors ${ }^{[36,37]}$ and especially salts, ${ }^{[31]}$ where strong 
Coulomb forces are dominant, excitons are trapped in low energy excited states and are prone to non-radiative recombination. On the contrary, free charge carriers at donoracceptor heterojunctions can only be generated, when electrons escape the Coulomb field, which was identified as the rate-limiting process in organic-salt-based photovoltaics. ${ }^{[38]}$ Considering the simple Coulomb equation for point charges shows that the Coulomb field is significantly dependent on the distance between cations and anions. ${ }^{[39]}$ Therefore, anions that lower the lattice energy and Coulomb interactions by spreading their charge over a large volume stabilize the excited state and reduce the binding energy of charge transfer states. It had also been shown that small point charges, such as anions, can introduce symmetry breaking within the polymethine chain and lead to a dipolar state. ${ }^{[40-43]}$

This work combines the two presented concepts, which leads to the creation of an organic/inorganic hybrid salt between a cyanine dye and a superweak coordinating anion unifying desirable properties from both classes of materials. Effects of the superweak coordinating anion on lattice energy, fluorescence intensity and fluorescence lifetime of spin-casted neat films as well as OPV device parameters are presented. This study allows the direct comparison among salts of 2-[5-(1,3-dihydro1,3,3-trimethyl-2H-indol-2-ylidene)-1,3-pentadien-1-yl]-1,3,3-trimethyl-3H-indolium chromophore between point like charge sulfonate anions with different organic moieties, the bistriflylimide with its negative charge delocalised over seven atoms and tetrakis(nonafluoro-tert-butoxy)aluminate introduced in this study with its negative charge spread over more than 36 atoms. Indeed, the superweak coordinating anion boosted the fluorescence intensity and quantum yield of neat spin-casted films as well as open circuit voltage, external quantum efficiency and performance of organic photovoltaic devices, as will be presented in further sections of this work. Most interestingly, linear correlations can be found between the lattice energy of the cyanine salts and 
fluorescence intensity as well as organic photovoltaic parameters allowing future predictions of these.

\section{Results and Discussion}

\subsection{Anion Exchange and Solid State Features}

The 2-[5-(1,3-dihydro-1,3,3-trimethyl-2H-indol-2-ylidene)-1,3-pentadien-1-yl]-1,3,3trimethyl-3H-indolium tetrakis(nonafluoro-tert-butoxy)aluminate (Cy5[Al(pftb) 4$]$ ) (Figure 1A) was obtained via a salt metathesis reaction in chlorobenzene (see Supporting information for the anion-exchange procedure).

Slow cooling of a saturated chlorobenzene solution yielded single crystals suitable for X-ray analysis. The $\mathrm{Cy} 5\left[\mathrm{Al}(\mathrm{pftb})_{4}\right]$ crystallizes in a monoclinic crystal system, space group $\mathrm{P} 2_{1} / \mathrm{c}$, with one chromophore anion pair per asymmetric unit, additionally containing two intercalated and disordered chlorobenzene molecules. Within two unit cells the packing of $\mathrm{Cy} 5\left[\mathrm{Al}(\mathrm{pftb})_{4}\right]$ shows well-separated chromophores due to the superweak coordinating anion, which prevents any close intermolecular interactions (Figure 1B).

A direct comparison of the bond length alternation of the $\mathrm{Cy} 5\left[\mathrm{Al}(\mathrm{pftb})_{4}\right]$ compound with different crystalized salts of the pentamethine chromophore, evaluated previously, ${ }^{[4]}$ shows surprisingly high values for the $\mathrm{Cy} 5\left[\mathrm{Al}(\mathrm{pftb})_{4}\right]$ compound (Figure 1C). While previous results suggested a clear trend towards the ideal polymethine state with increasing anion size, $\left[\mathrm{Al}(\mathrm{pftb})_{4}\right]^{-}$breaks the expected trend and introduces a similar bond length alternation as observed for the point charge like sulfonates or also other investigated anions (Figure 1C). ${ }^{[40,42,44]}$ Particularly the C9-C10 bond length possesses a pronounced single bond character including $\mathrm{Cy}_{5} \mathrm{O}_{3} \mathrm{SMe}$ and Cy5TFSI. These findings can relativize the until now assumed importance of bond length alternation based on single crystal structure data, since we do not observe any drawbacks neither in optical properties nor in organic photovoltaic parameters, as presented in the following. 
One way to physically express the qualitative meaning of "weakly coordinating” and to describe the interactions within a salt is to estimate their lattice energy. Single crystal data provides a unique opportunity to estimate molecular volume as well as to calculate lattice energy and Coulomb interactions of all crystalized pentamethine chromophore salts (Table S1, S2). These values can be correlated to photophysical or organic photovoltaic device properties allowing a general description of organic salt semiconductor properties. All presented values were estimated by a method described in the literature. ${ }^{[45,46]}$ As expected, the lattice energy represents the inverse of the molecular volume and reaches its minimum for the $\left[\mathrm{Al}(\mathrm{pftb})_{4}\right]^{-}$anion containing Cy5 salt.

\subsection{Optical and Thermal Properties}

Cy5[Al(pftb) 4 exhibits a high molar extinction coefficient of $3.55 \times 10^{5} \mathrm{~L} \mathrm{~mol}^{-1} \mathrm{~cm}^{-1}$ extracted from an absorption band ranging from 500 to $700 \mathrm{~nm}$ in ethanol solution, proving that the anion does not influence the optical properties; the latter being very similar to those in other salt solutions of this chromophore (Figure 2A, S3, Table S5, S6) ${ }^{[44]}$ Major differences lie in the UV-Vis solid state spectrum of $\mathrm{Cy} 5\left[\mathrm{Al}(\mathrm{pftb})_{4}\right]$, which is free of aggregates and approaches the monomeric state regarding the shoulder to peak ratio $\left(1: 0.72,1353 \mathrm{~cm}^{-1}\right)$ and band width of $5793 \mathrm{~cm}^{-1}$, which is only about $1669 \mathrm{~cm}^{-1}$ wider than the solution band width of $4124 \mathrm{~cm}^{-1}$. Applying the lattice energy concept in Figure 2B a first quantitative correlation against solid state optical properties is made, quantifying the anions' influence on the peak width. Photoluminescence spectra of $10 \mathrm{~nm}$ thick neat spin-cast films were recorded at 532 nm excitation wavelength (Figure S4). Photoluminescence measurements can be seen as a direct reflection of the individual anions' ability to stabilize the chromophore in the excited state (Figure 3A, B). Spin-casted film thicknesses of $10 \pm 1 \mathrm{~nm}$, as verified using spectroscopic ellipsometry paired with smooth and defect free film morphology, same light emitting chromophore, fixed laser excitation power as well as measurement setup allow 
comparing the dependence of photoluminescence properties on different anions. In comparison with the methane sulfonate anion as a benchmark, the variation of organic moieties increases the fluorescence intensity by a factor of 1.5 for the ${ }^{-} \mathrm{O}_{3} \mathrm{SNaphth}$ anion. Moderate improvement is achieved with the $\mathrm{TFSI}^{-}$anion, allowing a pronounced peak formation, achieving a 7-fold increase. When $\left[\mathrm{Al}(\mathrm{pftb})_{4}\right]^{-}$is employed, a clear emission peak enveloped boosting the intensity up to 5-times when compared to the TFSI anion containing salt. Additionally the lattice energy was found to be inversely proportional to the fluorescence intensity (Figure 3A). The absolute quantum yield follows this trend towards higher values with decreasing lattice energy (Table S8). A remarkable 6-fold increase in quantum yield can be observed from ${ }^{-} \mathrm{O}_{3} \mathrm{SMe}$ towards the superweak coordinating $\left[\mathrm{Al}(\mathrm{pftb})_{4}\right]^{-}$anion. However cyanine dye neat films are known for their low quantum yield making this measurement challenging and afflicted towards increased error, due to non-emissive decay pathways or quenching by hole transporting interlayers (Table S8). Additionally cyanine dye films casted on neat glass as required for the measurement form dewetted droplets introducing thickness fluctuations, self-absorbance and aggregate based quenching. On the contrary, fluorescence intensity can be relatively easily obtained by controlling the thickness and morphology of the cyanine film. However, fluorescence decay with a fluorescence lifetime of 0.75 ns could only be detected with the $\mathrm{Cy} 5\left[\mathrm{Al}(\mathrm{pftb})_{4}\right]$ compound due to the limited time resolution of $50 \mathrm{ps}$ of our detection system (Figure 3B). Accordingly, the sulfonate and bistriflylimide based salts must have radiative lifetimes shorter than 50 ps.

Cyanine dyes are able to exhibit unusual thermal behaviour when weakly coordinating anions are used. As already known, the melting point of the different pentamethine based cyanine salts presented in previous work lays above $150{ }^{\circ} \mathrm{C} \cdot{ }^{[44]}$ In principal, weakly coordinating anions are expected to lower the melting point mainly by preventing strong Coulomb interactions and closed packed stacking in the solid state. However this expected behaviour has to compete against the boosted molecular weight of the cyanine salt exceeding $1300 \mathrm{~g}$ 
$\mathrm{mol}^{-1}$. Indeed the melting point for $\mathrm{Cy} 5\left[\mathrm{Al}(\mathrm{pftb})_{4}\right]$ approaches $215^{\circ} \mathrm{C}$ which is an increase of $70{ }^{\circ} \mathrm{C}$ compared to previous investigated salts. ${ }^{[44]}$ The melting point is followed by two sharp peaks, an exothermic one at $269^{\circ} \mathrm{C}$ and an endothermal at $279^{\circ} \mathrm{C}$ (Figure 4). Such sequence of three peaks in the DSC indicates an evaporation process accompanied by a partial decomposition as already observed for a trimethine dye [Gesevicius et al, "unpublished"]. Within a temperature range of $225-269{ }^{\circ} \mathrm{C}$ a mass loss of $4 \%$ occurs in the TGA indicating melt evaporation followed by a rising amount of a degradation product with increasing temperature, leading to a broad one step degradation of the Cy5[Al(pftb $\left.)_{4}\right]$. Apparently, the extended polymethine chain leads to an additional thermal instability of the chromophore so that even the $\left[\mathrm{Al}(\mathrm{pftb})_{4}\right]^{-}$anion is not fully capable in bringing the chromophore to the vapour phase without observing a partial decomposition. It can only be speculated whether the fluoride bridged alkoxyaluminate dimer would decrease the lattice energy and the Coulomb interactions enough for that purpose of this hypothetical cyanine salt. ${ }^{[47,48]}$

\subsection{Anion Influence on Thin Film Morphology}

Weakly coordinating anions often contain perfluorinated moieties as does the $\left[\mathrm{Al}(\mathrm{pftb})_{4}\right]^{-}$. Combined with its size larger than $1 \mathrm{~nm}$, one expects the influence of the anion on the surface energy to become more significant. According to literature the aluminium core of the $\left[\mathrm{Al}(\mathrm{pftb})_{4}\right]^{-}$likewise increases the tendency in crystallization. ${ }^{[2,7,10]}$ Indeed, while the solubility in various solvents remained, substrate coating trials from various solvents revealed a strong tendency in either dendritic polycrystallite formation or pronounced dewetting when compared to the previous ${ }^{[44]}$ salts of the pentamethine chromophore (Figure 5, S5). Usual hole transport layers (HTL) such as $\mathrm{MoO}_{3}$ or PEDOT:PSS seem to provide a strong surface energy mismatch for the $\mathrm{Cy} 5\left[\mathrm{Al}(\mathrm{pftb})_{4}\right]$. Significant improvement yielding an amorphous and defect-free thin film was achieved employing $\mathrm{V}_{2} \mathrm{O}_{5}$ as HTL (Figure 5, S5). Films spin- 
cast from ethanol solution were stable over a sufficient time interval, allowing successful device fabrication. Both $\mathrm{MoO}_{3}$ and $\mathrm{V}_{2} \mathrm{O}_{5}$ show similar surface energies of 44.8 and $41.3 \mathrm{mN} \mathrm{m}^{-1}$, respectively. However, the disperse part of $\mathrm{V}_{2} \mathrm{O}_{5}$ is more pronounced contributing $35.2 \mathrm{mN} \mathrm{m}^{-1}$ to the surface free energy, while $\mathrm{MoO}_{3}$ seems to be more polar showing only $33.9 \mathrm{mN} \mathrm{m}^{-1}$ dispersive contribution. In fact, with $11 \mathrm{mN}$ $\mathrm{m}^{-1}$ the polar forces of $\mathrm{MoO}_{3}$ are almost twice as high when compared to $6.1 \mathrm{mN} \mathrm{m}{ }^{-1}$ observed in $\mathrm{V}_{2} \mathrm{O}_{5}$. Finally the $\mathrm{Cy} 5\left[\mathrm{Al}(\mathrm{pftb})_{4}\right]$ spin-casted on $\mathrm{V}_{2} \mathrm{O}_{5}$ yields a surface free energy of $36.9 \mathrm{mN} \mathrm{m}^{-1}$, of which the dispersive forces with $36.4 \mathrm{mN} \mathrm{m}^{-1}$ represent the major contribution. Stable Cy5[Al(pftb $\left.)_{4}\right]$ film formation on $\mathrm{V}_{2} \mathrm{O}_{5}$ probably originates from an improved match between the dispersive forces of the total surface free energy, which represents the majority contribution for both components.

\subsection{Anion Influence on OPV Device Performance}

Cy5[Al(pftb) $\left.)_{4}\right]$ proved to be a suitable electron donor for a bilayer organic photovoltaic device (Figure S6). Test devices under variation of hole transport layer $\left(\mathrm{V}_{2} \mathrm{O}_{5}\right)$ and active light absorbing layer thicknesses revealed an optimum value of $15 \mathrm{~nm}$ for both $\mathrm{V}_{2} \mathrm{O}_{5}$ and $\mathrm{Cy} 5\left[\mathrm{Al}(\mathrm{pftb})_{4}\right]$ (Figure S7, s8, s9). Under optimized conditions on four ITO substrates 8 cells per substrate were fabricated yielding 32 cells in total. 11 cells exhibited a short cut leaving 21 cells for analysis. Figure 6 depicts the current-voltage (JV) and external quantum efficiency (EQE) characteristics of the best performing cell. Low dark current of $1.1 \times 10^{-2} \mathrm{~mA} \mathrm{~cm}^{-2}$ at $-0.8 \mathrm{~V}$ points towards a compact morphology preventing alternative parasitic current pathways. An increased thickness also contributes to the reduction of possible defects within the light absorbing active layer. A high open circuit voltage $\left(\mathrm{V}_{\mathrm{OC}}\right)$ of $0.86 \mathrm{~V}$ and short circuit current $\left(\mathrm{J}_{\mathrm{SC}}\right)$ of 7.1 $\mathrm{mA} \mathrm{cm}{ }^{-2}$ with a solid fill factor $(\mathrm{FF})$ of $62 \%$ lead to a champion device performance ( $\eta$ ) of $3.8 \%$. This $40 \%$ increase in $\eta$ when compared to the Cy5TFSI device from 
previous work $^{[44]}$ is mainly driven by $21 \%$ enhancement in $\mathrm{V}_{\mathrm{OC}}$ and $16 \%$ in $\mathrm{FF}$, respectively. All parameters show little variation resulting in averaged values close to the champion device with small standard deviations (Table S9). Interestingly an active light absorbing layer thickness of $15 \mathrm{~nm}$ was found to be optimal, pointing towards an enhanced exciton diffusion length by the $\left[\mathrm{Al}(\mathrm{pftb})_{4}\right]^{-}$anion, which has also a supportive effect on the high $\mathrm{J}_{\mathrm{SC}}$ and FF values (Figure S9). This rise in exciton diffusion length points towards reduced Coulomb forces within $\mathrm{Cy} 5\left[\mathrm{Al}(\mathrm{pftb})_{4}\right]$ and less energetic disorder in films of this compound.

Both components contribute to the photovoltaic effect with an external quantum efficiency of $39 \%$ at $\lambda_{\max }$, wherein the major contribution originates from the dye in contrast to devices from previous work (Figure 6B) where the C60 contribution dominates. ${ }^{[4]}$ This major difference reflects the stabilization ability of the ${ }^{-} \mathrm{Al}(\mathrm{pftb})$ anion in cyanine dye based electronic devices. Furthermore, the calculated $\mathrm{J}_{\mathrm{SC}}$ of 5.7 $\mathrm{mA} \mathrm{cm}^{-2}$ from the EQE spectrum shows a good match with the averaged measured values.

Knowing the lattice energy of the organic salts allows comparing the OPV device parameters obtained from different salts on a universal energy scale (Figure 7). A linear correlation of $V_{O C}$ with the respective coefficient of determination $\left(R^{2}\right)$ of 0.97 is observed with decreasing lattice energy (Figure 7). Since $\mathrm{V}_{\mathrm{OC}}$ in the first instance can be seen as a material property, which is decoupled from the device architecture and fabrication steps, it becomes clear that the $\left[\mathrm{Al}(\mathrm{pftb})_{4}\right]^{-}$anion has the strongest influence on the HOMO level downshift towards a larger donor-acceptor energy gap, since it is the weakest coordinating anion known to be suitable for OPV applications. ${ }^{[49]} \mathrm{We}$ explain this phenomenon by reduced transfer integrals, which lead to a narrower distribution of HOMO and LUMO energy levels within the material. ${ }^{[50,51]}$ This decrease in energetic disorder causes a larger gap between HOMO and LUMO which 
results in a significant $\mathrm{V}_{\mathrm{OC}}$ gain. Large spacing between the molecules caused by the steric hindrance of the weakly coordinating anions and reduced Coulomb interactions favour weak molecular orbital overlaps, in contrast to conventional anions with localized negative charge.

Despite the linear increase of $V_{\text {oc }}$ and $\eta$, the $J_{\text {sc }}$ and the Fill Factor (FF) both exhibit additional losses for the sulfonate anions interrupting the linear correlation. These additional losses are most likely caused by exciton localization due to strong Coulomb forces and charge trapping in the disordered films incorporating point like charge sulfonate anions. In terms of the molecular arrangement the chromophores with sulfonate counterions experience significant attraction forces leading towards partial noncovalent chromophore overlap which causes aggregation phenomena. In good agreement stands also the non-measureable fluorescence intensity and excited state lifetimes of the sulfonate based salts. Shunting effects influencing the JV curve shapes cannot be neglected either. The FF also suffers from bimolecular recombination due to low mobility and interpenetrating phases as pointed out in the literature. ${ }^{[52]}$ However both $\mathrm{J}_{\mathrm{SC}}$ and $\mathrm{FF}$ are driven to their maximum for the Cy5 chromophore when $\left[\mathrm{Al}(\mathrm{pftb})_{4}\right]^{-}$is employed and approach the higher limit values for the FF found in organic semiconductors. ${ }^{[31,53]}$ In case of $\mathrm{Cy} 5\left[\mathrm{Al}(\mathrm{pftb})_{4}\right]$ the $\mathrm{J}_{\mathrm{sc}}$ thrives also due to the increased active light absorbing layer thickness of $15 \mathrm{~nm}$ and increased number of monomeric species within the amorphous film by reduction of aggregate formation visible from the solid state UV-Vis spectrum (Figure 2A, B).

Considering the efficiency which implements all the discussed JV parameters, a similar behaviour to the $\mathrm{V}_{\mathrm{OC}}$ is observed. A linear correlation with $\mathrm{R}^{2}$ of 0.99 down to a lattice energy of $319 \mathrm{~kJ} \mathrm{~mol}^{-1}$ representing the $\mathrm{Cy} 5\left[\mathrm{Al}(\mathrm{pftb})_{4}\right]$ is resulting in a high average value of $3.2 \%$ pointing towards highly efficient OPV devices naturally limited by device physics. ${ }^{[54]}$ 
An intriguing behaviour can also be found for the dielectric constant when correlated to the lattice energy of various Cy5 chromophore salts (Figure S12, Table S10). Since the dielectric constant is dependent on the Coulomb force and expresses the compounds' ability to be polarized, a drop occurs with decreasing lattice energy of the cyanine salts. Likewise the $\mathrm{Cy} 5\left[\mathrm{Al}(\mathrm{pftb})_{4}\right]$ which possesses the lowest dielectric constant shows also the highest performance of all investigated pentamethine cyanine salts in an OPV device.

The improved ability of converting the incident photons to charge carriers by tuning the lattice energy is very well represented for different salts of the Cy5 chromophore (Figure 7). The proportional rise of EQE $\left(\mathrm{R}^{2}=0.98\right)$ at $\lambda_{\max }$ of the investigated salts with decreasing lattice energy directly quantifies the ability of the superweak coordinating anion both by stabilizing the excited state and reducing charge transfer binding energy. We postulate that the linear correlated $V_{\mathrm{OC}}, \mathrm{EQE}$ and $\eta$ dependence on the lattice energy implements a new concept that can be generalized and used for prediction and simulation approaches considering any ionic semiconductor, as far as the device architecture is kept constant.

\section{Conclusion}

In this work two concepts were used to create an organic/inorganic hybrid salt semiconductor between a cyanine dye and a superweak coordinating anion unifying desirable properties from both classes of materials. Direct comparisons were made between salts of the Cy5 chromophore realized in previous work. Lattice energy was implemented as a general descriptor for organic salt semiconductor properties and setting first values for further refined calculations and experimental measurements. The superweak coordinating $\left[\mathrm{Al}(\mathrm{pftb})_{4}\right]^{-}$anion substantially lowers the lattice energy and Coulomb interactions of the pentamethine chromophore to its minimum. Excited state 
stabilization is reflected in the highest fluorescence intensity, absolute quantum yield as well as longest fluorescence lifetime for the $\mathrm{Cy} 5\left[\mathrm{Al}(\mathrm{pftb})_{4}\right]$ compound allowing an efficient exciton splitting at the dye/ $\mathrm{C}_{60}$ interface. Monomeric conditions are approached in the solid state yielding aggregate free and highly amorphous thin films with low overall surface roughness. All OPV figures of merit are boosted to their maxima for the pentamethine chromophore when $\left[\mathrm{Al}(\mathrm{pftb})_{4}\right]^{-}$anion is used, yielding a champion device with a power conversion efficiency of 3.8\%. Additionally $\mathrm{V}_{\mathrm{OC}}$, EQE and $\eta$ exhibited linear correlation when plotted against lattice energy. This proof of concept paves a future synthetic and descriptive pathway for all charged organic semiconductors and dyes whereever a highly stabilized excited state is needed.

\section{Experimental Section}

\subsection{Materials and Methods}

All chemicals and solvents were purchased from commercial sources (Aldrich, VWR, FEW Chemicals, Kurt J. Lesker) and used as received, unless otherwise stated. Reactions were carried out under air atmosphere using common lab glass ware. NMR multicore spectra were recorded on a Bruker $A V-400$ spectrometer $\left({ }^{1} \mathrm{H}-\mathrm{NMR}\right.$ : $400 \mathrm{MHz},{ }^{13} \mathrm{C}\left\{{ }^{1} \mathrm{H}\right\}-\mathrm{NMR}$ : $100 \mathrm{MHz}$, ${ }^{19} \mathrm{~F}\left\{{ }^{1} \mathrm{H}\right\}$-NMR: $\left.377 \mathrm{MHz}\right)$. Chemical shifts $(\delta)$ are reported in ppm (parts per million) with the solvent residual signal $\left({ }^{1} \mathrm{H} /{ }^{13} \mathrm{C}\left\{{ }^{1} \mathrm{H}\right\}: 7.20 / 79\right.$ for $\left.\mathrm{CDCl}_{3}\right)$ as reference. $\mathrm{J}$ coupling constants are given in Hz. Multiplicities are reported as singlet (s), doublet (d), triplet (t), quartet (q), multiplet (m). Thermal gravimetric analysis was recorded on a Netzsch TG 209 F1.

\subsection{Device Fabrication and Characterisation}

Glass/ITO substrates were cleaned in acetone (VWR, 99.5\% GPR RECTAPUR), isopropanol (VWR, EMPLURA), ethanol (VWR, 99.5\% AnalaR NORMAPUR ${ }^{\circledR}$ ), detergent (Hellmanex ${ }^{\circledR}$ III, 2 wt\% water solution) and finally washed four times with deionised water. Evaporation of $\mathrm{V}_{2} \mathrm{O}_{5}$ (99.97\%) hole transport layer and $\mathrm{C}_{60}$ (99.5\%) electron acceptor as well as tris(8- 
hydroxyquinolinato)aluminium (99.99\%) diffusion blocking layer and silver (99.99\%) as the top electrode were performed in a glovebox using vapour deposition techniques. The pressure in the evaporation chamber did not exceed $6 \times 10^{-6}$ mbar. The deposition rate was kept constant at $0.2 \AA \mathrm{s}^{-1}$. The active light absorbing layer was spin-coated at a constant speed of $4000 \mathrm{rpm}$ for $1 \mathrm{~min}$ in the glovebox under nitrogen atmosphere. The corresponding dye solutions (Figure S7) were prepared in the glovebox under nitrogen atmosphere and were filtrated over a $0.45 \mu \mathrm{m}$ filter before spin-casting. The cell areas were defined with 3.1 and $7.1 \mathrm{~mm}^{2}$ by using a mask for cathode deposition. The solar cells were characterised under inert gas atmosphere on a calibrated solar simulator (Spectra Nova) using a Xe lamp with $100 \mathrm{~mW} \mathrm{~cm}^{-}$

${ }^{2}$ simulated AM1.5G solar irradiation. The light intensity was adjusted using a calibrated silicon reference cell from Rera Solutions. External quantum efficiency was performed on a SpeQuest RR-2100.

\subsection{Further Characterisation}

UV-Vis spectra were measured on a Varian Cary 50. Measurement of $n$ and $k$ was performed using a spectroscopic ellipsometer M2000-VI (J.A. Woollam). The AFM analysis was performed on a scanning probe microscope Bruker Icon3 in tapping mode. Contact angle measurement and surface free energy calculation was performed on a Krüss Drop Shape Analyser. Single crystal diffraction patterns were recorded on a Stoe Mark II-Imaging Plate Diffractometer System (Stoe \& Cie, 2015) equipped with a graphite-monochromator. Data collection was performed at $-100^{\circ} \mathrm{C}$ using Mo-Ka radiation $(\lambda=0.71073 \AA)$. The structure was solved by direct methods using the program SHELXS and refined by full matrix least squares on $\mathrm{F}^{2}$ with SHELXL using the graphical user interface Olex2. ${ }^{[55,56]}$ The hydrogen atoms were included in calculated positions and treated as riding atoms using SHELXL-97 default parameters. All non-hydrogen atoms were refined anisotropically. CCDC 1858881 contains the supplementary crystallographic data for $\mathrm{Cy} 5\left[\mathrm{Al}(\mathrm{pftb})_{4}\right]$. These data can be obtained free of charge from The Cambridge Crystallographic Data Centre via 
www.ccdc.cam.ac.uk/data_request/cif. Detailed information of the described experiments can be found in the supporting information.

Photoluminescence spectra were measured with a CCD fiber spectrometer (LR1, Aseq Instruments) with a $638 \mathrm{~nm} \mathrm{CW}$ laser diode. PL emission from the samples passed through a long-pass optical filter with an edge at $650 \mathrm{~nm}$ in order to reject the excitation laser line. Time-resolved photoluminescence (TRPL) traces were recorded with a 532 nm excitation source (a frequency-doublet, Nd:YAG laser, Duetto from TimeBandwidth). Scattered laser emission was filtered out using dielectric long-pass filters with edges at $550 \mathrm{~nm}$. Measurements were performed using a time-correlated single photon counting (TCSPC) setup, equipped with a SPC-130-EM counting module (Becker \& Hickl GmbH) and an IDQ-ID-100-20-ULN avalanche photodiode (Quantique) for recording the decay traces. Absolute values of the photoluminescence quantum yield (PLQY) were measured with a Quantaurus-QY C11347 spectrometer from Hamamatsu in low-QY mode with excitation by an external broadband Xe-lamp filtered by short-pass filter with edge at $650 \mathrm{~nm}$.

\section{Supporting Information}

Supporting Information is available from the Wiley Online Library or from the author.

\section{Acknowledgements}

The use of the Scanning Probe Microscopy User Laboratory at Empa is gratefully acknowledged. We thank the Swiss National Science Foundation for financial support under grant number 160116.

Received: ((will be filled in by the editorial staff))

Revised: ((will be filled in by the editorial staff)) Published online: ((will be filled in by the editorial staff)) 


\section{References}

[1] M. R. Rosenthal, J. Chem. Educ. 1973, 50, 331.

[2] T. S. Cameron, A. Decken, I. Dionne, M. Fang, I. Krossing, J. Passmore, Chem. - A Eur. J. 2002, 8, 3386.

[3] I. M. Riddlestone, A. Kraft, J. Schaefer, I. Krossing, Angew. Chemie Int. Ed. 2018, 57, 13982.

[4] S. H. Strauss, Chem. Rev. 1993, 93, 927.

[5] A. M. Bond, S. R. Ellis, A. F. Hollenkamp, 1988, 5293.

[6] I. Krossing, I. Raabe, Angew. Chemie - Int. Ed. 2004, 43, 2066.

[7] T. A. Engesser, M. R. Lichtenthaler, M. Schleep, I. Krossing, Chem. Soc. Rev. 2016, 45, 789.

[8] C. Reed, Acc. Chem. Res. 1998, 4842, 133.

[9] S. Körbe, P. J. Schreiber, J. Michl, Chem. Rev. 2006, 106, 5208.

[10] I. Krossing, In Comprehensive Inorganic Chemistry II; Elsevier, 2013; pp. 681-705.

[11] E. Y.-X. Chen, S. J. Lancaster, Comprehensive Inorganic Chemistry II; 2013.

[12] C. WINTER, X. ZHOU, M. HEEG, Organometallics 1991, 10, 3799.

[13] I. B. Gorrell, G. Parkin, Inorg. Chem. 1990, 29, 2452.

[14] P. V. Bonnesen, P. V. Bonnesen, C. L. Puckett, C. L. Puckett, R. V. Honeychuck, R. V. Honeychuck, W. H. Hersh, W. H. Hersh, J. Am. Chem. Soc. 1989, 111, 6070.

[15] R. F. Jordan, W. E. Dasher, S. F. Echols, J . Am. Chem. 1986, 108, 1718.

[16] G. Fachinetti, T. Funaioli, P. F. Zanazzi, J. Chem. Soc., Chem. Commun. 1988, 081, 1100.

[17] P. Kölle, H. Nöth, Chem. Rev. 1985, 399.

[18] A. . Fallis, J. Chem. Inf. Model. 2013, 53, 1689.

[19] D. Dubois, K. M. Kadish, S. Flanagan, R. E. Haufler, L. P. F. Chibante, L. J. Wilson, J. Am. Chem. Soc. 1991, 113, 4364.

[20] C. Jehoulet, A. J. Bard, F. Wudl, J. Am. Chem. Soc. 1991, 113, 5456.

[21] I. Krossing, Chemistry 2001, 7, 490.

[22] N. Karl, Mol. Cryst. Liq. Cryst. Inc. Nonlinear Opt. 1989, 171, 31.

[23] S. R. Forrest, IEEE J. Sel. Top. Quantum Electron. 2000, 6, 1072.

[24] J. Roncali, P. Leriche, P. Blanchard, Adv. Mater. 2014, 26, 3821.

[25] D. Saccone, S. Galliano, N. Barbero, P. Quagliotto, G. Viscardi, C. Barolo, European J. Org. Chem. 2016, 2016, 2244.

[26] J. L. Bricks, A. D. Kachkovskii, Y. L. Slominskii, A. O. Gerasov, S. V. Popov, Dye. Pigment. 2015, 121, 238. 
[27] U. Lawrentz, W. Grahn, K. Lukaszuk, C. Klein, R. Wortmann, A. Feldner, D. Scherer, Chem. - A Eur. J. 2002, 8, 1573.

[28] R. V. Markov, P. A. Chubakov, A. I. Plekhanov, Z. M. Ivanova, N. A. Orlova, T. N. Gerasimova, V. V. Shelkovnikov, J. Knoester, Nonlinear Opt. 2000, 25, 365.

[29] M. Young, J. Suddard-Bangsund, T. J. Patrick, N. Pajares, C. J. Traverse, M. C. Barr, S. Y. Lunt, R. R. Lunt, Adv. Opt. Mater. 2016, 4, 1028.

[30] O. Malinkiewicz, T. Grancha, A. Molina-Ontoria, A. Soriano, H. Brine, H. J. Bolink, Adv. Energy Mater. 2013, 3, 472.

[31] M. Bates, R. R. Lunt, Sustain. Energy Fuels 2017, 1, 955.

[32] J. Suddard-Bangsund, C. J. Traverse, M. Young, T. J. Patrick, Y. Zhao, R. R. Lunt, Adv. Energy Mater. 2016, 6, 1501659.

[33] C. J. Traverse, M. Young, J. Suddard-Bangsund, T. Patrick, M. Bates, P. Chen, B. Wingate, S. Y. Lunt, A. Anctil, R. R. Lunt, Sci. Rep. 2017, 7, 16399.

[34] A. Köhler, H. Bässler, Electron. Process. Org. Semicond. 2015, 87.

[35] S. G. Lias, P. Ausloos, J. Am. Chem. Soc. 1978, 100, 6027.

[36] X. Y. Zhu, Q. Yang, M. Muntwiler, Acc. Chem. Res. 2009, 42, 1779.

[37] O. V Mikhnenko, P. W. M. Blom, T.-Q. Nguyen, Energy Environ. Sci. 2015, 8, 1867.

[38] A. Devižis, J. De Jonghe-Risse, R. Hany, F. Nüesch, S. Jenatsch, V. Gulbinas, J.-E. Moser, J. Am. Chem. Soc. 2015, 137, 8192.

[39] G. Spavieri, G. T. Gillies, M. Rodriguez, Metrologia 2004, 41, S159.

[40] P.-A. Bouit, C. Aronica, L. Toupet, B. Le Guennic, C. Andraud, O. Maury, J. Am. Chem. Soc. 2010, 132, 4328.

[41] O. D. Kachkovski, O. I. Tolmachov, Y. L. Slominskii, M. O. Kudinova, N. O. Derevyanko, O. O. Zhukova, Dye. Pigment. 2005, 64, 207.

[42] T. D. Iordanov, J. L. Davis, A. E. Masunov, A. Levenson, O. V. Przhonska, A. D. Kachkovski, Int. J. Quantum Chem. 2009, 109, 3592.

[43] A. E. Masunov, D. Anderson, A. Y. Freidzon, A. A. Bagaturyants, J. Phys. Chem. A 2015, 119, 6807.

[44] D. Gesevičius, A. Neels, S. Jenatsch, E. Hack, L. Viani, S. Athanasopoulos, F. Nüesch, J. Heier, Adv. Sci. 2018, 5, 1700496.

[45] H. D. B. Jenkins, H. K. Roobottom, J. Passmore, L. Glasser, Inorg. Chem. 1999, 38, 3609.

[46] I. Krossing, J. M. Slattery, C. Daguenet, P. J. Dyson, A. Oleinikova, H. Weingärtner, J. Am. Chem. Soc. 2006, 128, 13427.

[47] A. Bihlmeier, M. Gonsior, I. Raabe, N. Trapp, I. Krossing, Chem. - A Eur. J. 2004, 10, 5041.

[48] A. Martens, P. Weis, M. C. Krummer, M. Kreuzer, A. Meierhöfer, S. C. Meier, J. Bohnenberger, H. Scherer, I. Riddlestone, I. Krossing, Chem. Sci. 2018, 9, 7058. 
[49] J. Suddard-Bangsund, C. J. Traverse, M. Young, T. J. Patrick, Y. Zhao, R. R. Lunt, Adv. Energy Mater. 2016, 6, 1501659.

[50] J. L. Bredas, J. P. Calbert, D. A. da Silva Filho, J. Cornil, Proc. Natl. Acad. Sci. 2002, 99, 5804.

[51] A. Troisi, G. Orlandi, J. Phys. Chem. A 2006, 110, 4065.

[52] J. Nelson, Mater. Today 2011, 14, 462.

[53] B. Qi, J. Wang, Phys. Chem. Chem. Phys. 2013, 15, 8972.

[54] S. M. Menke, N. A. Ran, G. C. Bazan, R. H. Friend, Understanding Energy Loss in Organic Solar Cells: Toward a New Efficiency Regime. Joule 2018, 2, 25-35.

[55] G. M. Sheldrick, Acta Crystallogr. Sect. C Struct. Chem. 2015, 71, 3.

[56] O. V. Dolomanov, L. J. Bourhis, R. J. Gildea, J. A. K. Howard, H. Puschmann, IUCr, J. Appl. Crystallogr. 2009, 42, 339.

A)

C)
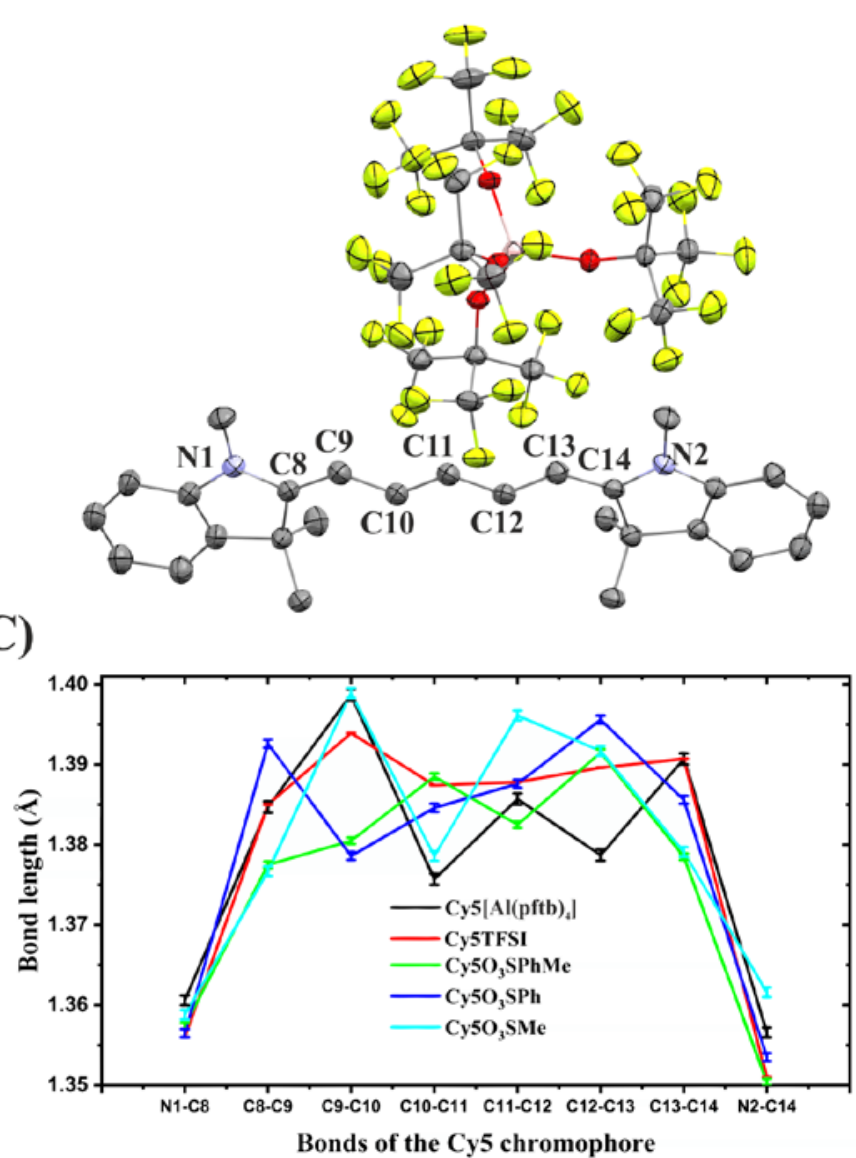

B)

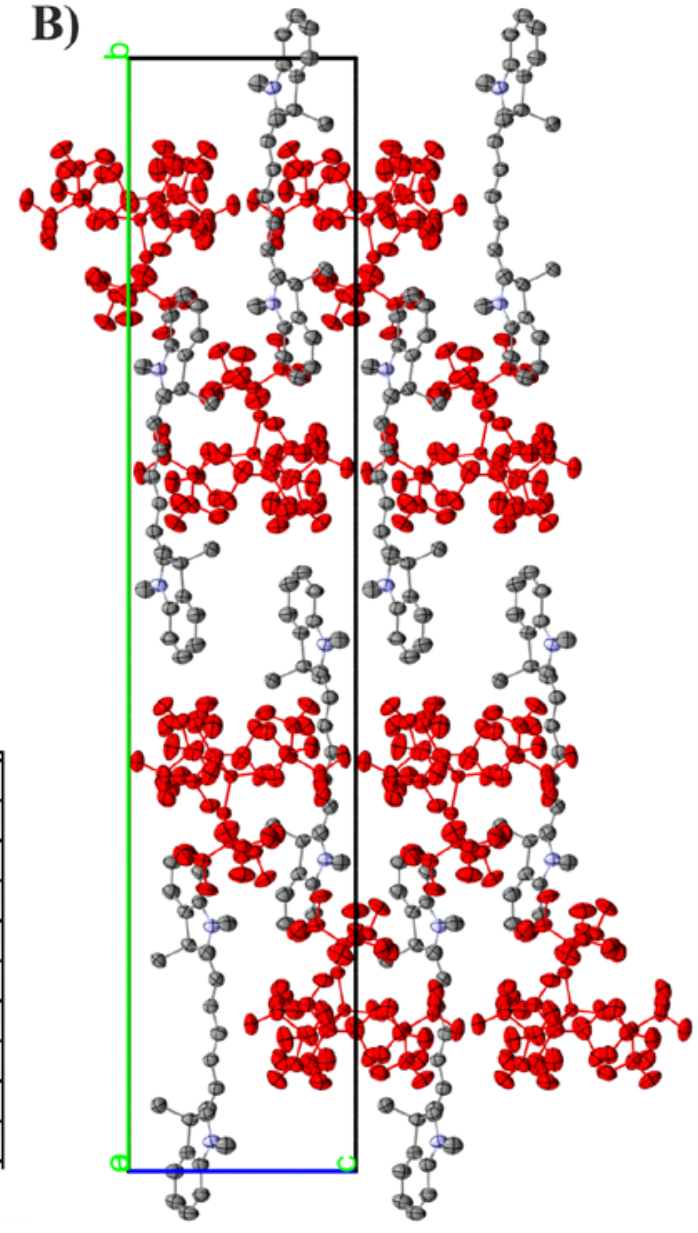

Figure 1. A) Asymmetric unit representing the $\mathrm{Cy} 5\left[\mathrm{Al}(\mathrm{pftb})_{4}\right]$ in ellipsoid view with $30 \%$ probability level. The hydrogen atoms and intercalated chlorobenzene solvent molecules are 
omitted for clarity. Color code: C: grey, N: violet, O: red, F: yellow, Al: purple. B) Molecular arrangement of $\mathrm{Cy} 5\left[\mathrm{Al}(\mathrm{pftb})_{4}\right]$ over $2 \mathrm{x} 1 \mathrm{x} 2$ unit cells in ellipsoid view with $30 \%$ probability level. Hydrogen atoms and intercalated chlorobenzene solvent molecules are omitted. Color code chromophore: C. grey, $\mathrm{N}$, violet. The anions are colored red for clarity reasons. C) Bond length alternation comparison between different salts of the Cy5 chromophore.
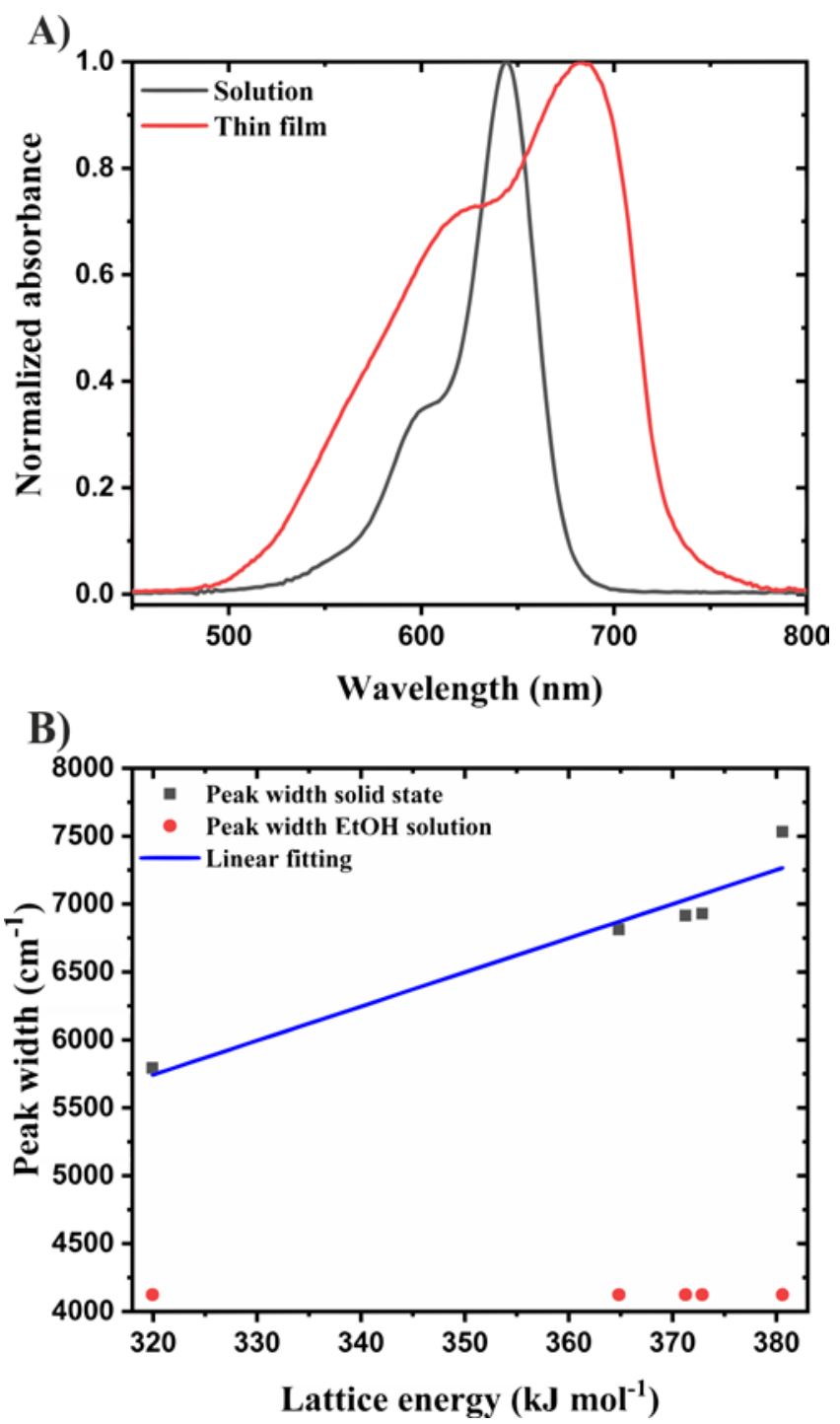

Figure 2. A) Normalized UV-Vis absorbance spectra of $\mathrm{Cy} 5\left[\mathrm{Al}(\mathrm{pftb})_{4}\right]$ from ethanol solution and $15 \mathrm{~nm}$ thick spin-casted film. B) UV-Vis solid state absorbance bandwidth dependence on lattice energy and comparison with the bandwidth in solution $\left(\mathrm{R}^{2}: 0.93\right.$ and Pearson's $\left.\mathrm{r}: 0.96\right)$. The lattice energy represents the following materials: $\mathrm{Cy}_{5} \mathrm{O}_{3} \mathrm{SMe}\left(380.57 \mathrm{~kJ} \mathrm{~mol}^{-1}\right)$, 
$\mathrm{Cy}_{5} \mathrm{O}_{3} \mathrm{SPh}\left(372.84 \mathrm{~kJ} \mathrm{~mol}^{-1}\right), \mathrm{Cy}_{5} \mathrm{O}_{3} \mathrm{SPhMe}\left(371.24 \mathrm{~kJ} \mathrm{~mol}^{-1}\right)$, Cy5TFSI (364.83 kJ mol$\left.{ }^{-1}\right)$, $\mathrm{Cy5}\left[\mathrm{Al}(\mathrm{pftb})_{4}\right]\left(319.92 \mathrm{~kJ} \mathrm{~mol}^{-1}\right)$.
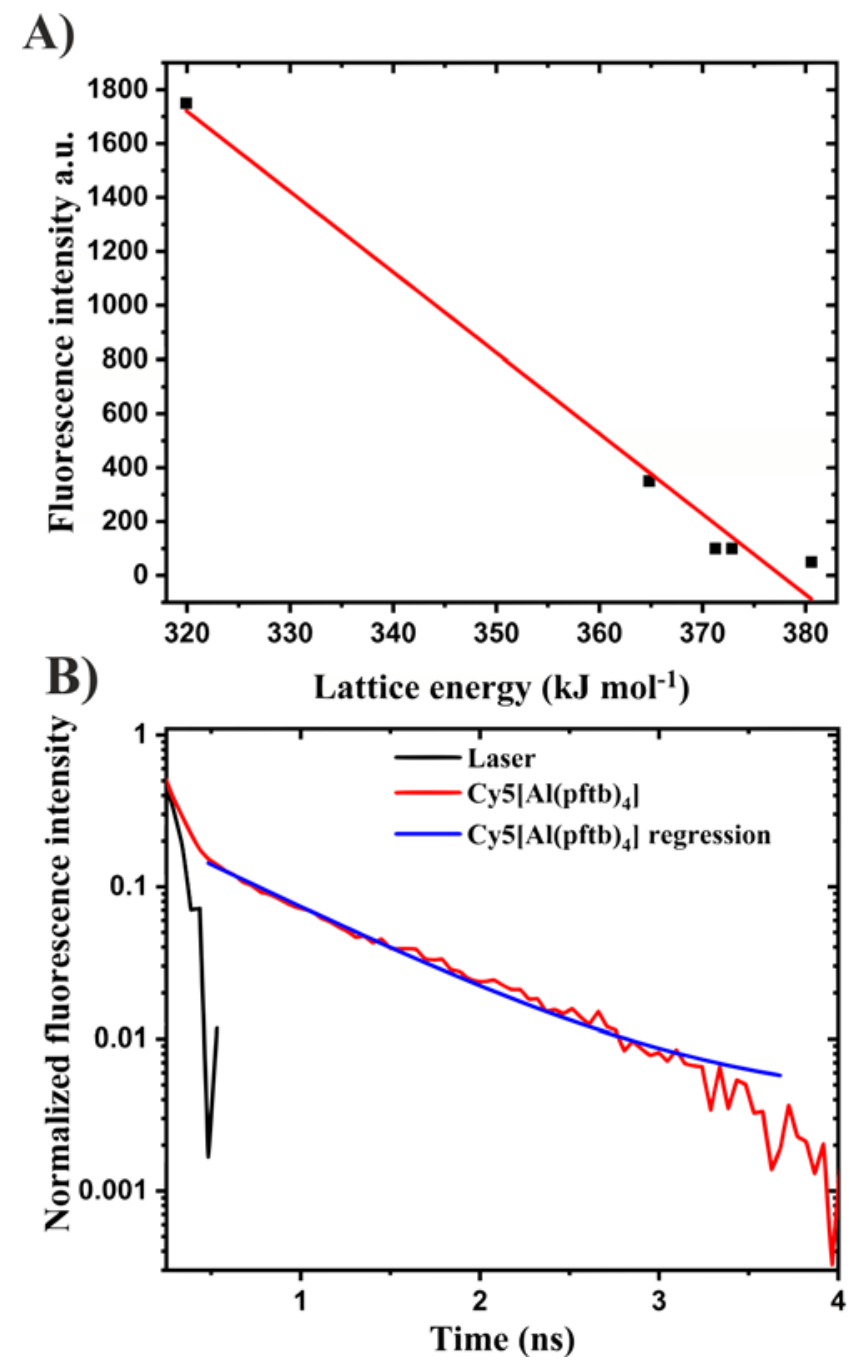

Figure 3. A) Fluorescence intensity obtained at $709 \mathrm{~nm}$ emission maxima from $10 \mathrm{~nm}$ thick spin-casted films plotted against the lattice energy of the corresponding Cy5 salts with $\mathrm{R}^{2}$ of 0.99 and Pearson's $\mathrm{r}$ of -0.99 . The lattice energy represents the following materials: $\mathrm{Cy}_{5} \mathrm{O}_{3} \mathrm{SMe}\left(380.57 \mathrm{~kJ} \mathrm{~mol}^{-1}\right), \mathrm{Cy}_{5} \mathrm{O}_{3} \mathrm{SPh}\left(372.84 \mathrm{~kJ} \mathrm{~mol}^{-1}\right), \mathrm{Cy}^{2} \mathrm{O}_{3} \mathrm{SPhMe}\left(371.24 \mathrm{~kJ} \mathrm{~mol}^{-1}\right)$, Cy5TFSI (364.83 kJ mol$\left.{ }^{-1}\right), \mathrm{Cy5}\left[\mathrm{Al}(\mathrm{pftb})_{4}\right]\left(319.92 \mathrm{~kJ} \mathrm{~mol}^{-1}\right)$. B) Fluorescence lifetime of $\mathrm{Cy} 5\left[\mathrm{Al}(\mathrm{pftb})_{4}\right]$. The exponential regression has the form $\mathrm{y}=3.79 \times 10^{-3}+1.49 \times 10^{-1} \times \exp (-(\mathrm{x}-$ $\left.4.37 \times 10^{-1}\right) / 7.51 \times 10^{-1}$ with a $\mathrm{R}^{2}$ of 0.99 . 


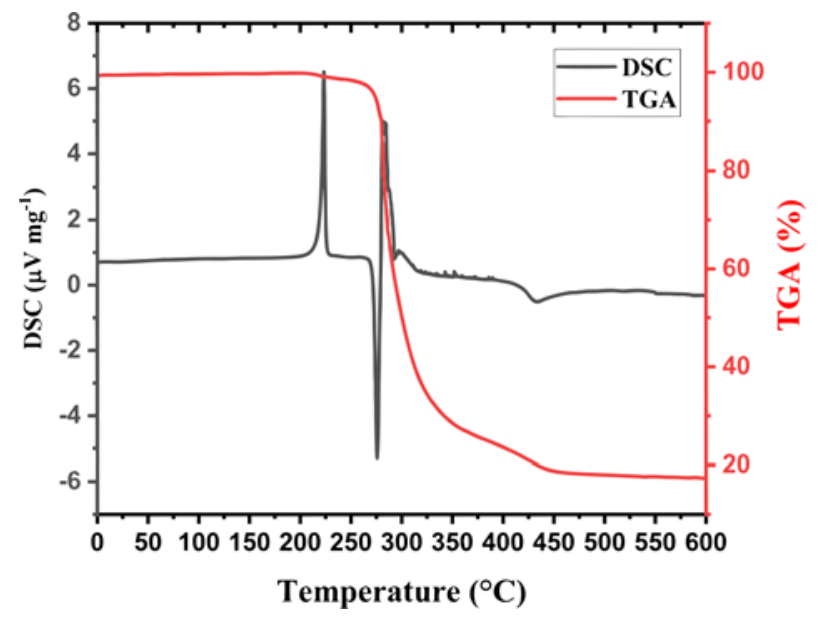

Figure 4. In situ thermogravimetric analysis and differential scanning calorimetry (endo up) of $\mathrm{Cy} 5\left[\mathrm{Al}(\mathrm{pftb})_{4}\right]$.
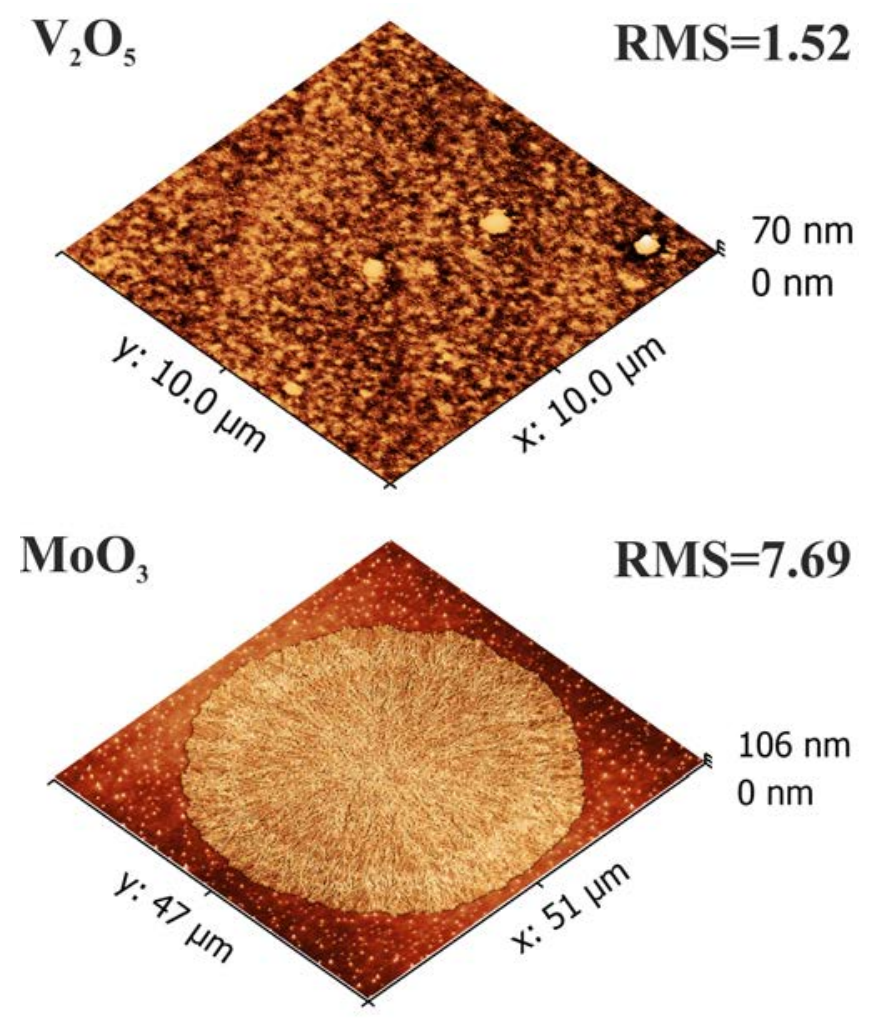

Figure 5. AFM images of spin-casted $\mathrm{Cy} 5\left[\mathrm{Al}(\mathrm{pftb})_{4}\right]$ films on V2O5 and MoO3 substrates. On $\mathrm{MoO}_{3}$ a dendritic crystal is observed. 
A)

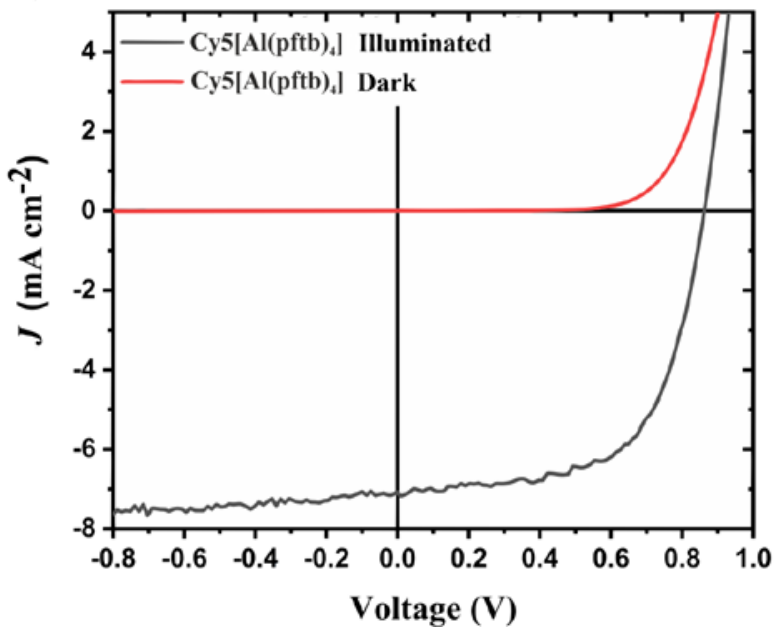

B)

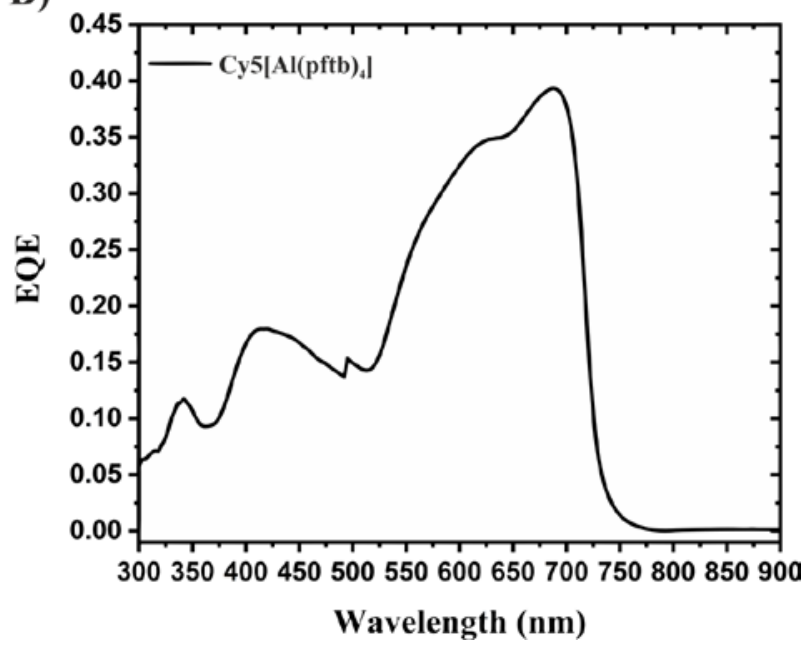

Figure 6. Current density vs. Voltage and external quantum efficiency plots of the best performing Cy5[Al(pftb) $\left.)_{4}\right]$ cell.

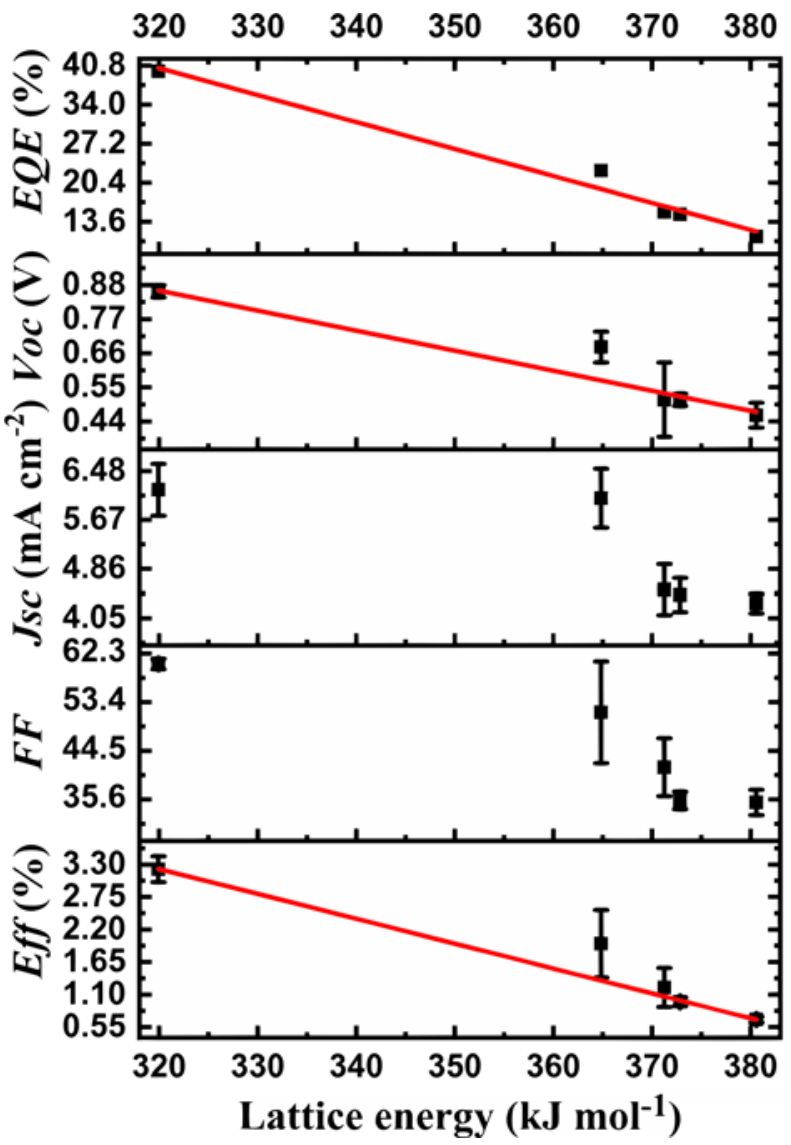

Figure 7. OPV device parameters plotted against lattice energy of various Cy5 salts. The lattice energy represents the following materials: $\mathrm{Cy}_{5} \mathrm{O}_{3} \mathrm{SMe}\left(380.57 \mathrm{~kJ} \mathrm{~mol}^{-1}\right), \mathrm{Cy}_{5} \mathrm{O}_{3} \mathrm{SPh}$ (372.84 $\left.\mathrm{kJ} \mathrm{mol}^{-1}\right), \mathrm{Cy} 5 \mathrm{O}_{3} \mathrm{SPhMe}\left(371.24 \mathrm{~kJ}^{-1}\right)$, Cy5TFSI (364.83 $\left.\mathrm{kJ} \mathrm{mol}^{-1}\right)$, 
Cy5[Al(pftb) 4 ] (319.92 $\left.\mathrm{kJ} \mathrm{mol}^{-1}\right)$. Each data point for EQE, FF, $\mathrm{J}_{\mathrm{sc}}, \mathrm{V}_{\text {oc }}$ and Eff $(\eta)$ contain averaged values with their standard deviation. The data points for EQE were taken from best performing cells at maximum conversion wavelength. The linear correlation curves in red have an $\mathrm{R}^{2} /$ Pearson's $\mathrm{r}$ of $0.98 /-0.99,0.97 /-0.99$ and 0.99/-0.99 for EQE, $\mathrm{V}_{\mathrm{OC}}$ and Eff $(\eta)$ respectively.

\section{TOC entry:}

Lattice energy is introduced as a general descriptive parameter for fluorescence intensity, quantum yield, external quantum efficiency, open circuit voltage and performance of ionic organic semiconductors. A general energy scale allows the decoupling from a certain molecular structure and enables predictions of a complex system.

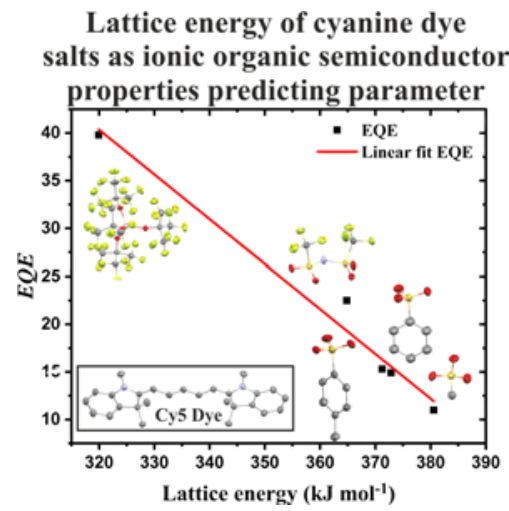

